
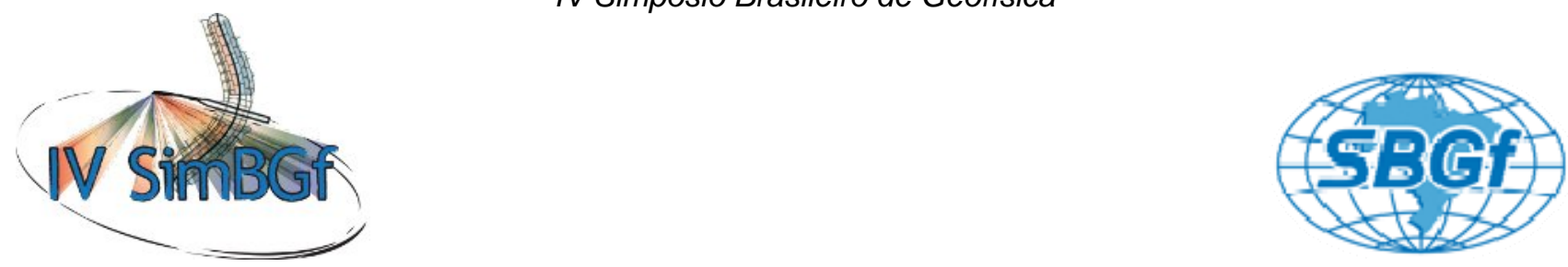

\title{
Verificação da viabilidade do método GPR para o mapeamento de camadas que compõem os depósitos de bauxita laterítica
}

\author{
Gildenilson Mendes Duarte, UFPA, INCT-GP \\ José Gouvêa Luiz, UFPA \\ Clóvis Mauriti, Vale \\ Dário de Castro, Vale \\ Marcos Welby Correa Silva, UFPA, INCT-GP
}

Copyright 2010, SBGf - Sociedade Brasileira de Geofísica

Este texto foi preparado para a apresentação no IV Simpósio Brasileiro de Geofísica, Belém, 14 a 17 de novembro de 2010. Seu conteúdo foi revisado pelo Comitê Técnico do IV SimBGf, mas não necessariamente representa a opinião da SBGf ou de seus associados. É proibida a reprodução total ou parcial deste material para propósitos comerciais sem prévia autorização da SBGf.

\section{Abstract}

GPR profiles were carried out in the Paragominas Lateritic Bauxite Province, in Paragominas county, estate of Pará. A profile run on a bauxite deposit covered by around $12 \mathrm{~m}$ of a clay layer did not reach the bauxite mineralization. A second profile run on a place with no clay cover gave good results allowing to the discrimination of the bauxite rich layers, suggesting that the GPR can give important information on the lateritic bauxite deposits and contribute to help the explotation work.

\section{Introdução}

O estudo das rochas que ocorrem à superfície do solo (afloramentos) bem como de suas relações no espaço e no tempo é de fundamental importância para a compreensão de rochas de subsuperfícies e, portanto, para a localização de depósitos de minérios. No entanto, os afloramentos nem sempre podem nos fornecer informações seguras sobre a subsuperfície e no caso de partes da Amazônia, podem não se encontrar disponíveis devido ao processo de intemperismo ali presente.

A escassez de depósitos de minerais aflorantes ou pouco profundos levou à necessidade de se desenvolver mecanismos que proporcionassem a descoberta de depósitos mais profundos desenvolvendo-se, a partir daí, a Geofísica de Exploração.

Geralmente as rochas diferem entre si por meio de suas propriedades físicas, o que provocam variações em seus campos físicos, bem como na propagação de ondas que incidem sobre as mesmas. $E$ através das respostas obtidas devido à interação entre campos e ondas, podemos adquirir informações acerca dos materiais que provocaram essas respostas (Luiz \& Silva, 1995). Essas interações entre campos e ondas podem ser identificadas através da utilização de métodos geofísicos como, por exemplo, o método GPR (Ground Penetrating Radar), que é um método eletromagnético que emprega elevadas freqüências e foi utilizado neste trabalho.

Existem numerosas aplicações dos métodos elétricos e eletromagnéticas seja na área ambiental (detecção de plumas contaminantes), prospecção de água subterrânea e também exploração mineral que é o foco de nosso trabalho. O tipo de mineração aqui investigado é um depósito de bauxita laterítica. O objetivo deste trabalho é verificar a viabilidade da aplicação do método GPR para o mapeamento das camadas que compõem as bauxitas lateríticas, identificando, assim, parâmetros como, profundidades e espessuras, que podemauxiliar no trabalho de explotação do minério. Os levantamentos foram realizados na região da Província Bauxitífera de Paragominas-PA, nas proximidades da BR 010. Esta região contém formações sedimentares que sustentam os platôs, que são feições geomórficas dominantes na região (Kotschoubey, et al, 2005).

\section{Localização da Área e Geologia Local}

A área investigada faz parte da Provícia Bauxitífera de Paragominas (Figuras 1 e 2) que é caracterizada por formações sedimentares que sustentam os platôs, feições geomorfológicas dominantes na região. O perfil litológico na área investigada é composto por uma espessa camada argilosa (Argila de Belterra), seguida de um Horizonte Pisolítico, uma camada de bauxita nodular, laterita ferruginosa, bauxita cristalizada, zona de bauxita cristalizada lamorfa, bauxita amorfa e, por fim, argila variegada. A figura 3 mostra o perfil litológico da área destacando também a espessura estimada de cada camada. Uma característica importante a ser observada é o fato da existência de três tipos de bauxita. Outra característica marcante na área estudada é a presença de camadas onduladas e descontínuas. 


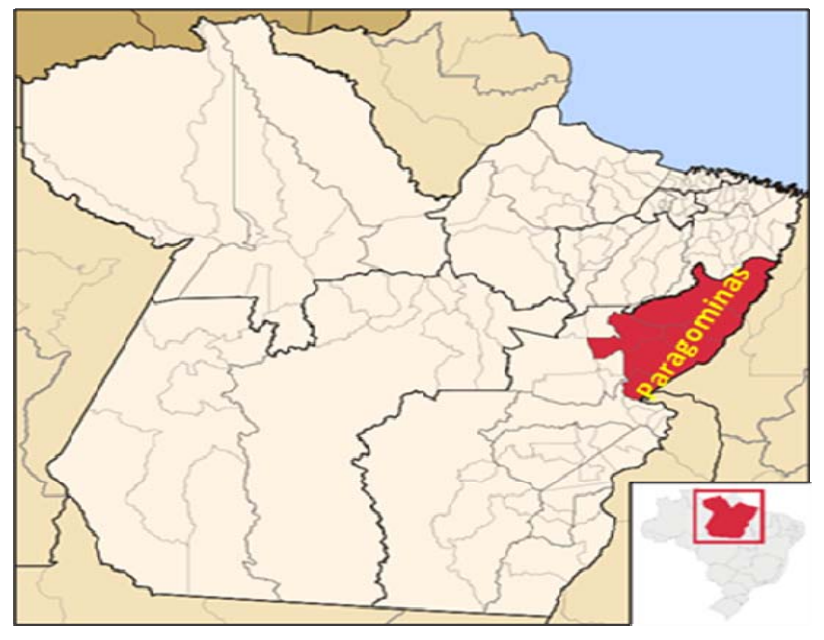

Figura 1 - Mapa do Estado do Pará destacando a localização do município de Paragominas. Modificado de commons.wikimedia.org/wiki/File:Para_Micro_Pa.

\section{Metodologia}

Utilizamos, nesse trabalho, o método GPR (Ground Penetrating Radar) ou método Georadar que consiste na radiação de ondas eletromagnéticas por uma antena transmissora (Tx) posta às proximidades da superfície a ser investigada. Essas ondas interagem com os materiais da subsuperfície que podem possuir diferentes propriedades eletromagnéticas, sofrendo reflexão, refração e difração. As ondas refletidas que retornam à superfície são captadas por outra antena, a receptora $(\mathrm{Rx})$, que pode estar acoplada à antena receptora ou posta separada da mesma. As frequências usadas no método GPR normalmente variam de 15 a 2500 Megahertz (MHz). O comportamento dessa onda, como a sua profundidade de penetração, sua reflexão e refração, ao penetrar o solo, depende de sua freqüência e das propriedades eletromagnéticas do meio investigado. Quanto maior for a frequência da onda eletromagnética que penetra o solo, maior será a sua interação com o meio e, portanto, maior será a dissipação de sua energia o que ocasiona uma menor penetração. Por outro lado, essa profundidade alcançada depende também das propriedades eletromagnéticas do meio. Por exemplo, se o meio for condutivo a onda sofre o que chamamos de atenuação, indicando que a mesma entrou numa zona de alta perda alcançando uma baixa profundidade (o inverso é verdadeiro). A velocidade de propagação da onda é governada pela permissividade relativa do meio (Daniels, 1996). Outra característica do método está relacionada à resolução dos dados obtidos. Quanto maior for a frequência da onda maior será a resolução obtida, permitindo a identificação de interfaces menos separadas e de pequenos objetos.

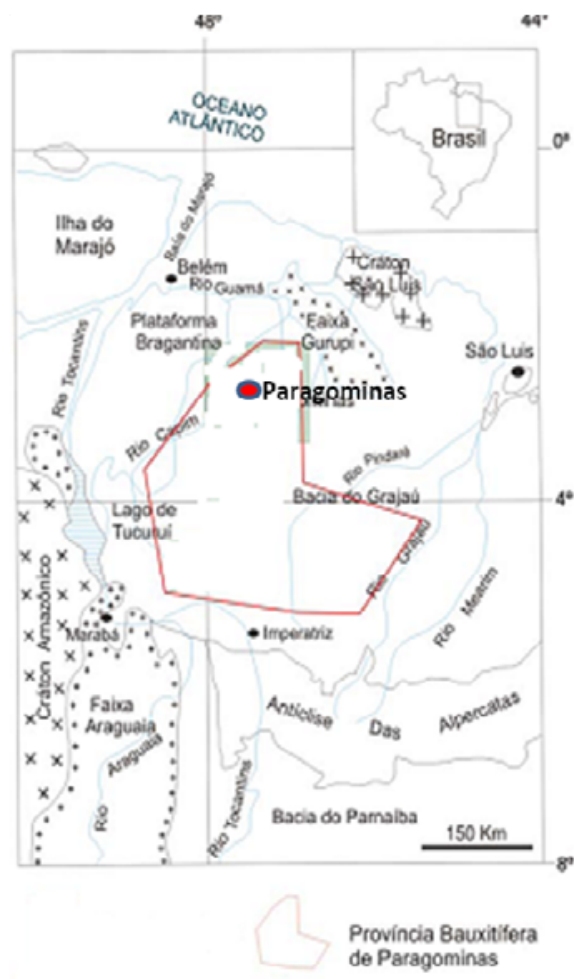

Figura 2 - Mapa destacando a Província Bauxitífera de Paragominas. Modificado de KOTSCHOUBEY, et al, 2005.

No presente trabalho, utilizamos uma antena de 200 $\mathrm{MHz}$ blindada e o equipamento TerraSirch SIR System 3000, da Geophysical Survey Sistems (Figura 4), operando no modo tempo e contínuo. A investigação foi feita ao longo de uma linha de $50 \mathrm{~m}$, com marcações a intervalos de $5 \mathrm{~m}$ e janela de tempo de $150 \mathrm{~ns}$.

O processamento do dado de GPR foi feito por meio do software Reflexw, versão 5.5.5.1 da K. J. Sandmeier. Foi feita a correção estática, um ganho de energia de decaimento, interpolação das marcas, filtros 1-D bandpassbutterworth e subtract-mean (dewow), filtros 2D running average e background removal. A velocidade utilizada, no processamento, foi de 0,08 $\mathrm{m} / \mathrm{ns}$, determinada por meio do método da hipérbole, resultando num valor de $0,08 \mathrm{~m} / \mathrm{ns}$.

\section{Resultados}

Durante a pesquisa, um perfil com o GPR foi realizado em local onde havia capeamento argiloso de cerca de $12 \mathrm{~m}$ sobre a zona mineralizada. O perfil mostrou que é inviável alcançar a zona mineralizada com a antena de $200 \mathrm{MHz}$, pois a condutividade elétrica da argila atenuou a onda do GPR antes que fosse alcançada a mineralização. Optou-se, então, por realizar um perfil em local sem a presença do capeamento. Esse perfil é mostrado na Figura 5. Observa-se na seção de GPR 
interfaces que devem representar as camadas mostradas no perfil litológico. A seção mostra também que, na área estudada, as camadas apresentam descontinuidades e ondulações.

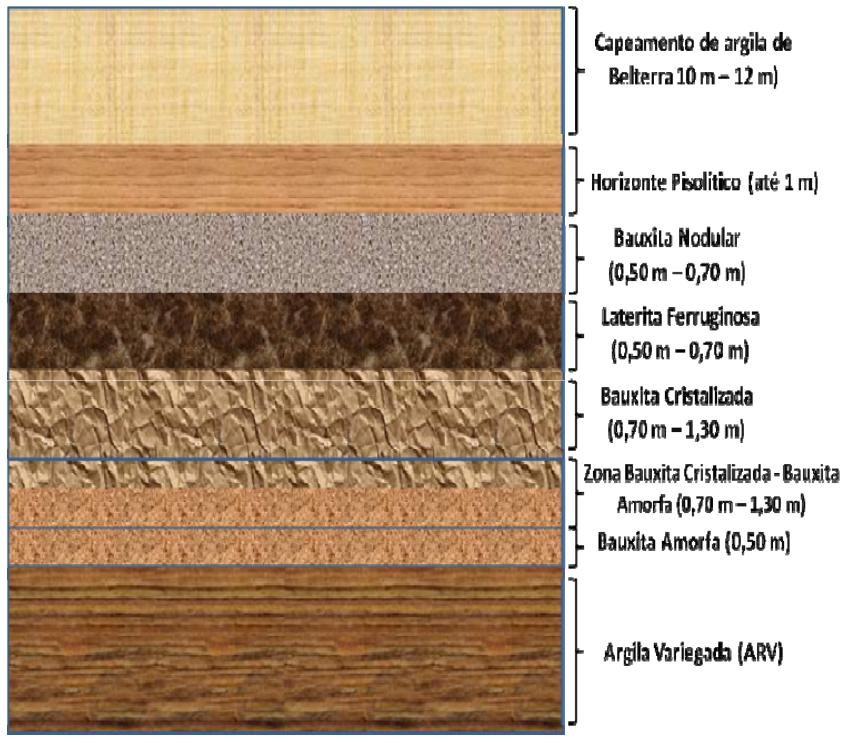

Figura 3 - Desenho esquemático do perfil litológico da área estudada.

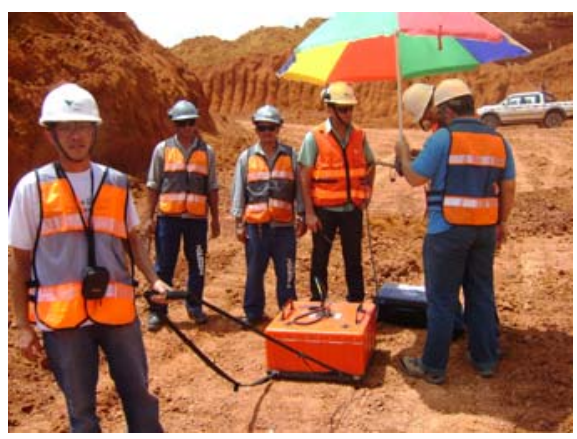

Figura 4 - Antena de GPR de $200 \mathrm{MHz}$ utilizada na aquisição dos dados.

A interpretação do perfil foi realizada a partir da sua correlação com o perfil litológico da área em estudo. Assim, integrando-se os dados obtidos a partir da seção de GPR (Figura 5) com o modelo esquemático da Geologia das camadas do local (Figura 3), e usando-se informações obtidas em três poços perfurados nas posições 0, 25 e $50 \mathrm{~m}$ do perfil, foi possível identificar as seguintes camadas: bauxita cristalizada (BC), transição entre bauxita cristalizada e bauxita amorfa (BC/BA), bauxita amorfa (BA) e argila variegada.

\section{Conclusões}

Com a utilização do método GPR, obtivemos uma boa resposta no que diz respeito à profundidade alcançada e à resolução da imagem. A aquisição de dados foi bem sucedida também em relação à rapidez e praticidade no levantamento de campo, uma vez que dispusemos de uma antena na qual já são acopladas a antena transmissora (Tx) e a receptora (Rx), desse modo, necessitando de um número mínimo de operadores.

Com a utilização da antena blindada de $200 \mathrm{MHz}$ não foi possível obter informações sobre a zona do minério no local onde havia capeamento argiloso de espessura aproximada de $12 \mathrm{~m}$, devido à atenuação da onda eletromagnética transmitida pelo GPR.

A aplicação do método GPR foi satisfatória no que diz respeito ao mapeamento das camadas que compõem o depósito de bauxita. As camadas foram bem caracterizadas no radargrama, o que nos possibilitou estimar as espessuras, suas descontinuidades e comprovar suas ondulações conforme as informações à priori, fornecidas por poços.

A correlação entre a seção de GPR e o perfil litológico da área estudada foi obtida satisfatoriamente. Foi possível associar a sequência de camadas obtidas no radargrama com a do perfil litológico.

Com os dados que obtivemos, concluímos que é possível a utilização do método GPR, para a prospecção mineral de bauxita laterítica.

\section{Agradecimentos}

Ao Programa de Pós-graduação em Geofísica do Instituto de Geociências da UFPA pela oportunidade de desenvolvimento dessa pesquisa e ao Departamento de Operações Bauxita Paragominas da Empresa Vale pelo suporte financeiro da logística de nosso trabalho e por ceder a área de sua mina de Bauxita para a realização de nossas investigações. Ao técnico Paulo Magalhães pela importante assistência no trabalho de campo. Ao CNPq por estar proporcionando uma bolsa para o mestrando Gildenilson Mendes Duarte, para o desenvolvimento de sua pesquisa e ao INCT-GP pelo suporte para a apresentação deste trabalho.

\section{Referências}

DANIELS, D. J. 1996. Surface Penetrating Radar. The Institution of Electrical Engineers, London, United Kingdom, 72 pp..

KOTSCHOUBEY et al. 1997. Caracterização e Gênese dos Depósitos de Bauxita da Província bauxitífera de Paragominas, Nordeste da bacia do Grajaú, Nordeste do Pará/Oeste do Maranhão. In: MARINI, O.J.; QUEIROZ, E.T.; RAMOS, B.W. (Coord.), Caracterização de depósitos minerais em distritos mineiros da Amazônia, capítulo 11, p. 687-782. Brasília: ADIMB/DNPM. 
LUIZ, J. G.; SILVA, M. C. S. 1995. Geofísica de

Prospecção. Vol. 1. Universidade Federal do Pará. Cejup.

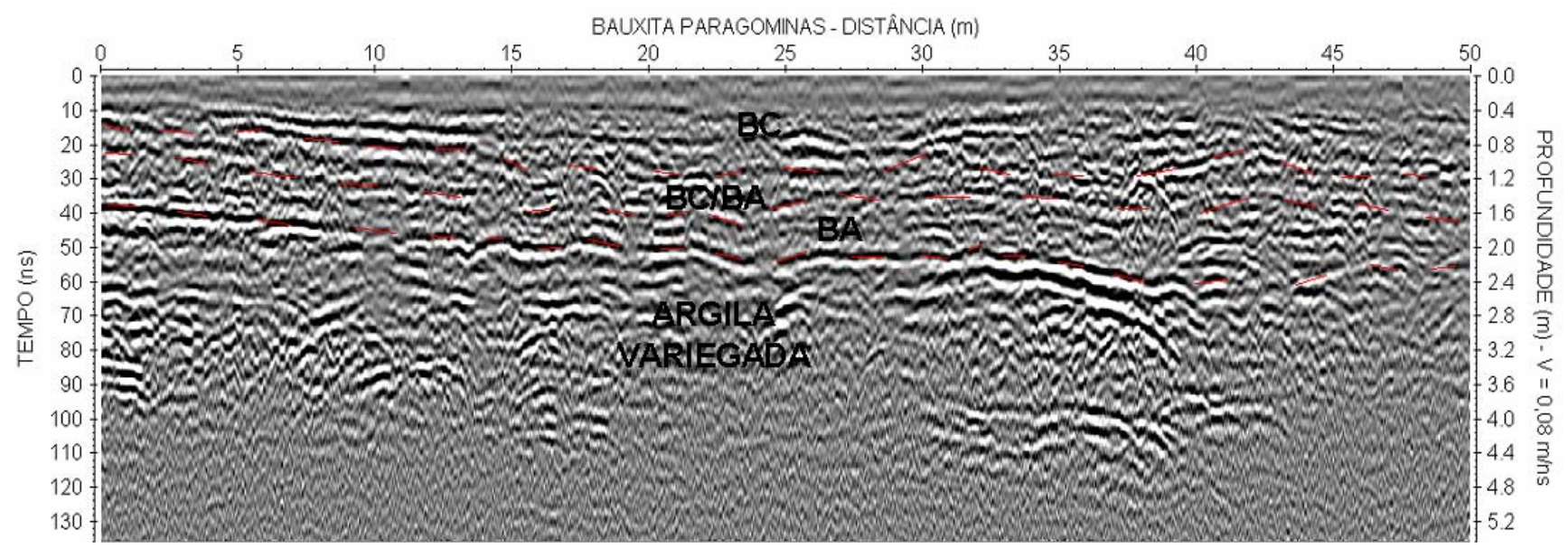

Figura 5 - Seção obtida com o GPR na Mina Bauxita Paragominas. BC - bauxita cristalizada; BC/BA - transição entre bauxita cristalizada e bauxita amorfa; BA - bauxita amorfa. 